\title{
Experimental hydrothermal alteration of crystalline and radiation-damaged pyrochlore
}

\author{
T. Geisler a , A.-M. Seydoux-Guillaume ${ }^{\text {b }}$, P. Poeml ${ }^{\text {a }}$, U. Golla-Schindler ${ }^{\text {a }}$, \\ J. Berndt ${ }^{\mathrm{a}}$, R. Wirth ${ }^{\mathrm{c}}$, K. Pollok ${ }^{\mathrm{a}}$, A. Janssen ${ }^{\mathrm{a}}$, and A. Putnis ${ }^{\mathrm{a}}$ \\ ${ }^{a}$ Institut für Mineralogie, University of Münster, Corrensstraße 24, D-48149 Münster, Germany \\ ${ }^{\mathrm{b}}$ LMTG-UMR 5563 CNRS, Université Paul Sabatier, 39, allée Jules Guesde, 31000 Toulouse, France \\ ${ }^{c}$ GeoForschungsZentrum Potsdam, Telegrafenberg, D-14473 Potsdam, Germany
}

\begin{abstract}
We have performed hydrothermal experiments with a crystalline microlite and a heavily self-irradiation-damaged (i.e., X-ray amorphous) betafite in a solution containing $1 \mathrm{~mol} / \mathrm{l} \mathrm{HCl}$ and $1 \mathrm{~mol} / \mathrm{L} \mathrm{CaCl}_{2}$ at $175^{\circ} \mathrm{C}$. The well-crystalline microlite grains were partly $(\sim 5-10 \mu \mathrm{m}$ rim) replaced by a Ca and Na-poorer, defect pyrochlore phase with a larger unit-cell and a sharp chemical gradient at the interface (on a nm scale) to the unreacted core. The amorphous betafite grains (up to $\sim 2 \mathrm{~mm}$ in diameter), on the other hand, were completely transformed into an intergrowth of different crystalline phases (polycrystalline anatase and rutile, a yet unidentified Nb-Ta oxide, and a Y-REE phase), showing complex non-equilibrium structures. Our experimental observations resemble those made on natural samples. They indicate that the processes of the fluid-pyrochlore interaction are influenced by self-irradiation structural damage and that thermodynamic equilibrium models can hardly be applied to adequately describe such systems.
\end{abstract}

\section{Introduction}

Considering the enormous amounts of high-level nuclear waste accumulated worldwide in the past decades, solutions for its safe immobilisation are urgently needed. Pyrochlore is a component of some Synroc versions (i.e., titanate-based ceramics [1]) and has been proposed as immobilization matrix for excess weapons-grade plutonium. Although considerable effort has been put to understanding radiation damage effects in pyrochlore [2], almost nothing is known about the effect of radiation damage on fundamental atomic mechanisms causing the aqueous alteration features seen in natural samples [3,4].

When a solid phase interacts with a fluid, several reaction mechanisms are possible, depending on the physicochemical conditions of the fluid, but also on the structural and thermodynamic properties of the solid phase (e.g., "porosity" of the structure, defect concentration, degree of amorphization, elastic strain). The simplest process that can occur is stoichiometric dissolution, following the breaking of cation-oxygen bonds controlled by protonation or de-protonation of the surface. Stoichiometric dissolution can be spatially coupled with precipitation of a thermodynamically more stable phase at a moving front. In other cases, the solid-fluid interaction is controlled by complex diffusion-reaction processes (often referred to as "leaching" reactions), which occur while the parent phase is in the solid state. The importance of each of these mechanisms during the interaction of crystalline and radiation-damaged pyrochlore with a hydrothermal fluid has not yet been fully understood.

In this contribution, we present data from crystalline and radiation-damaged pyrochlore treated at $175^{\circ}$ in an acidic solution. The aim of the study was to investigate the influence of self-irradiation damage on the mechanisms and kinetics of the pyrochlore-fluid interaction.

\section{Experimental details}

\subsection{Analytical methods}

The starting material and the run products were studies by powder X-ray diffraction (XRD) analyses, electron microprobe (EMP), Raman spectroscopy, and transmission electron microscopy (TEM). The focussed ion beam (FIB) technique was used to prepare electron transparent foils from the reaction products [5]. The U, Ta and $\mathrm{Ti}$ content in the experimental fluid was analysed by inductive-coupled plasma optical emission spectroscopy (ICP-AES). Details of the analytical procedures are given in Geisler et al. [6]. All errors are given at the $2 \sigma$ level. 

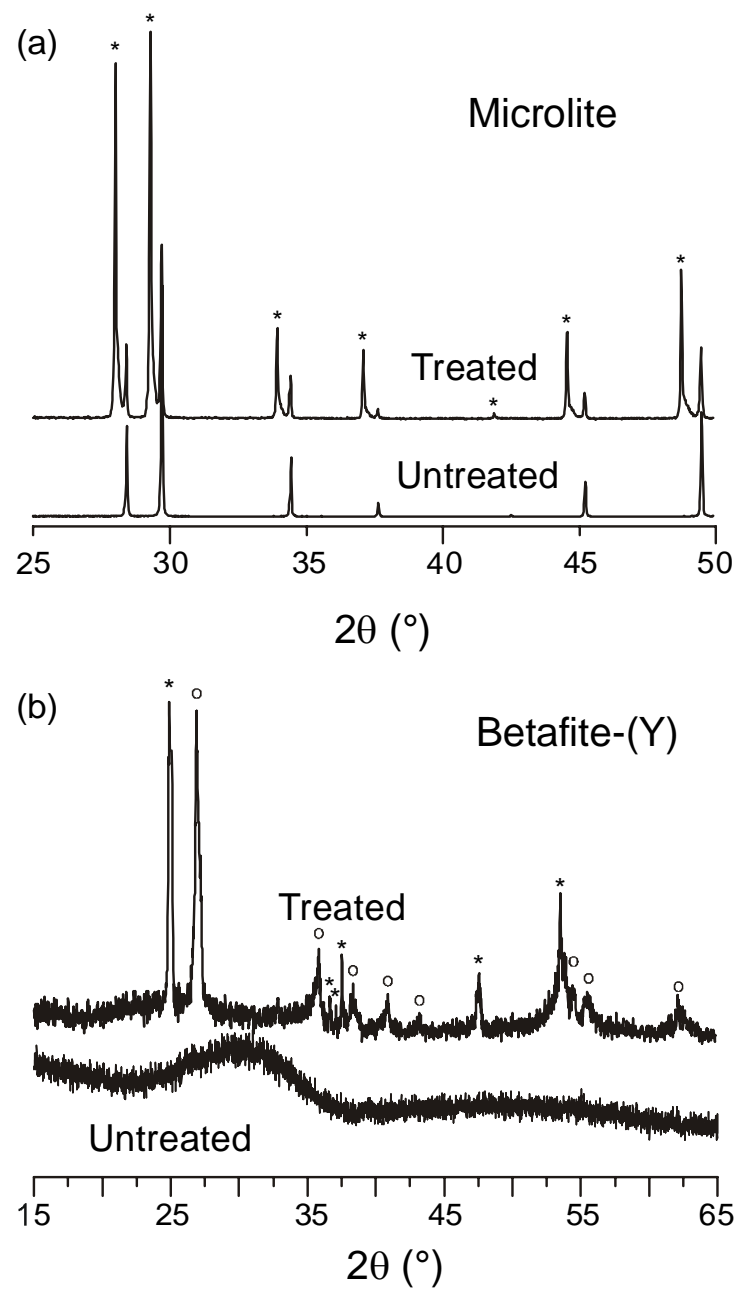

Fig. 1. Powder X-ray diffraction patterns of the untreated and hydrothermally treated (a) microlite (data from [5]) and (b) betafite-(Y) sample. The HasterisksH in (a) mark new peaks belonging to a new pyrochlore phase with a larger unit-cell. The HasterisksH and circles in (b) mark diffraction peaks, which belong to anatase and rutile, respectively.

\subsection{Starting material}

We have performed hydrothermal experiments with an $\mathrm{X}$-ray amorphous betafite-(Y) from a rare earth pegmatite from Lindvikskollen near Kragerø, South Norway and a crystalline microlite from an evolved granite near Lueshe, Republic of Congo.

The crystalline microlite was virtually unaltered. The empirical structural formula obtained from 32 EMP analyses is

$$
\begin{aligned}
& \left(\mathrm{Ca}_{1.23} \mathrm{Na}_{0.75} \mathrm{~A}_{0.02}\right)\left(\mathrm{Ta}_{1.78} \mathrm{Nb}_{0.08} \mathrm{Ti}_{0.08} \mathrm{Si}_{0.06}\right)_{\Sigma=2} \mathrm{O}_{6.28} \mathrm{X}, \mathrm{Y}_{0.15} \\
& \mathrm{~F}_{0.57}
\end{aligned}
$$

with $\mathrm{A}=\mathrm{Sr}, \mathrm{Pb}, \mathrm{Y}$ and $\mathrm{Fe}$. The structural formula was computed on the assumption that $\Sigma \mathrm{B}=2$. The sample further contains $\sim 150 \mathrm{ppm} \mathrm{U}$ and $\sim 700 \mathrm{ppm}$ Th. The XRD pattern shows sharp diffraction signals (Fig. 1a). More details about this sample are given in Geisler et al. [6].

In contrast, the XRD spectrum of the betafite-( $\mathrm{Y}$ ) shows no Bragg diffraction peaks, even after counting $90 \mathrm{~s}$ per $0.02^{\circ} 2 \theta$ step. Instead, two very broad diffraction humps occur at about $30^{\circ}$ and $50^{\circ} 2 \theta$ (Fig. 1b), which are typical for heavily damaged, i.e. metamict pyrochlore [7]. Surprisingly, electron diffraction patterns obtained from powder drilled from unaltered areas exhibit in some cases minor reflections (not shown here), which could unambiguously be assigned to pyrochlore.

In contrast to the microlite, the betafite-(Y) exhibits already severe alteration features. The altered areas occur along cracks and as large patchy zones (Fig. 2a). They are characterized by lower backscattered electron (BSE) intensity. Chemically, the alteration zones can be distinguished from unaltered areas by significantly higher Ca contents, which is typical feature for primary alteration of pyrochlore and microlite at temperatures between 350 and $650^{\circ} \mathrm{C}$ [1]. The altered areas also give slightly lower analytical totals and, in many cases, have gained Si. EMP analyses of the unaltered areas $(n=146)$ gave following average empirical structural formula (based on $\Sigma \mathrm{B}=2$ ):

$\left(\mathrm{Y}_{0.52} \mathrm{REE}_{0.23} \mathrm{U}_{0.16} \mathrm{Ca}_{0.07} \mathrm{Fe}_{0.06} \mathrm{Th}_{0.04} \mathrm{~Pb}_{0.03}{ }^{\mathrm{A}}{ }_{0.89}\right)\left(\mathrm{Ti}_{1.24} \mathrm{Nb}_{0.69}\right.$ $\left.\mathrm{Ta}_{0.05} \mathrm{Zr}_{0.01}\right)_{\Sigma=2} \mathrm{O}_{6.05} \mathrm{X,Y} \quad 0.95 \cdot 0.65 \mathrm{H}_{2} \mathrm{O}$

where REE are rare earth elements (e.g., 0.63 wt. $\% \mathrm{Lu}_{2} \mathrm{O}_{3}$, 1.19 wt.\% $\mathrm{Ho}_{2} \mathrm{O}_{3}, 1.33$ wt.\% $\mathrm{Gd}_{2} \mathrm{O}_{3}, 2.59$ wt.\% $\mathrm{Dy}_{2} \mathrm{O}_{3}$, 1.75 wt.\% $\mathrm{Er}_{2} \mathrm{O}_{3}$, and 2.84 wt.\% $\mathrm{Yb}_{2} \mathrm{O}_{3}$ ). $\square$ represents a vacancy.

We have estimated a U-Th-total $\mathrm{Pb}$ model age of 1020 $\pm 10 \mathrm{Ma}$ from the $\mathrm{U}$, Th, and $\mathrm{Pb}$ content of 134 analyses of the unaltered areas. This age is in good agreement with $\mathrm{U} / \mathrm{Pb}$ ages obtained from minerals of other REE-rich granite pegmatites in South Norway and SouthwestSweden [8]. From the age and the average $U$ and Th concentration we have estimated that the sample has experienced an average cumulated $\alpha$-decay dose of (38.7 $\pm 4.2) \times 10^{19} \alpha$-decays/g.

We are aware that the betafite-(Y) is not an ideal sample since the experimental alteration is superimposed on the natural alteration. However, we will show that this will not affect the main conclusions drawn in this paper.

\subsection{Experimental methods}

The experiments were carried out with powder and two larger grains $(1-4 \mathrm{~mm})$ and a solution containing $1 \mathrm{~mol} / \mathrm{l}$ $\mathrm{HCl}$ and $1 \mathrm{~mol} / \mathrm{l} \mathrm{CaCl}_{2}$ in Teflon reactors at $175 \pm 3^{\circ} \mathrm{C}$ 

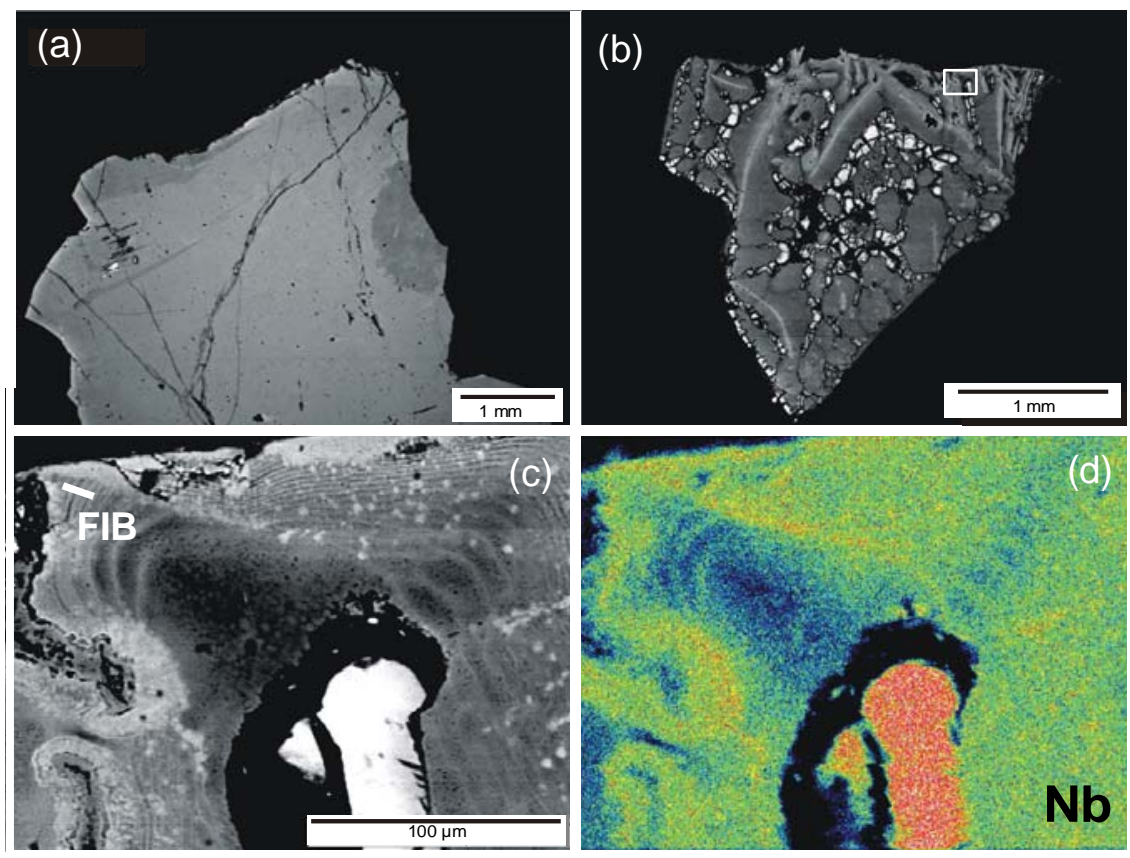

Fig. 2. Backscattered electron (BSE) and elemental distribution images of untreated and hydrothermally treated grains of the radiationdamaged betafite-(Y) sample. (a) BSE image of a grain of the untreated betafite - (Y) sample. Note that this sample has already been altered during its geological history. The alteration zones give a lower BSE intensity and spread out along cracks, but also appear as lager patchy areas. (b) Hydrothermally treated betafite - (Y) grain. The hydrothermal treatment has caused the complete transformation into an intergrowth of Nb-rich anatase and rutile and unidentified Nb-Ta and Y-REE phases, which are reflected by various grey scales in the BSE image. The white square marks the magnified section of the BSE and the element distribution image shown in (c) and (d), respectively. (c) BSE image of the area marked in (b) by a rectangle. The location of the electron transparent foil prepared by the focussed ion beam (FIB) technique for transmission electron microscope (TEM) investigations is marked. Note the porosity in the banded areas. (d) Nb distribution image of the area shown in (c). The unidentified Nb-Ta oxide phase appears in the lower middle part of the image.

under autogeneous pressures $(<50$ bar). Such a solution can be considered as a simplified natural fluid composition. The fluid-powder weight ratio was $\sim 20$. A second run at the same conditions yielded identical results, confirming the reproducibility of the experiments.

\section{Results and Discussion}

Fig. 1 shows the powder XRD pattern from the experimental run products compared with the pattern from the untreated material. In the XRD spectrum of the hydrothermally treated microlite new diffraction peaks occur at the low $2 \theta$ side of each peak observed in the untreated microlite, indicating that a new pyrochlore phase with a larger unit-cell volume crystallized (Fig. 1a). BSE images of individual grains reveal that this new pyrochlore phase partly replaces the microlite grains (Fig. 3). The thickness of the replacement varies between about 5 to 10 $\mu \mathrm{m}$. This new pyrochlore phase was found to be characterized by significantly lower Ca (Fig. 3b), Na, and F concentrations and a high amount of A-site vacancies and molecular water [6]. The average structural formula of the new defect pyrochlore as determined by EMP analyses is

$\left(\mathrm{Ca}_{0.33} \mathrm{Na}_{0.04} \mathrm{~A}_{0.02}{ }^{\mathrm{A}} \square_{1.61}\right)\left(\mathrm{Ta}_{1.77} \mathrm{Nb}_{0.09} \mathrm{Ti}_{0.09} \mathrm{Si}_{0.06}\right)_{\Sigma=2} \mathrm{O}_{5.20}$

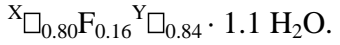

Geisler et al. [6] have demonstrated that the experimental alteration resembles low-temperature alteration features of natural pyrochlore-group minerals from world-wide localities. The chemical alteration of natural samples has been explained by selective "leaching" of A site cations associated with hydration as a consequence of a remarkable stability of the $\mathrm{B}_{2} \mathrm{X}_{6}$ framework of the pyrochlore structure [3,4]. Geisler et al. [5] further discussed the experimental results within the framework of (i) the proposed leaching mechanism and (ii) a coupled dissolution-reprecipitation (D-R) process that operates at a moving interface [9]. The latter process is often associated with the development of porosity, irrespectively of the relative molar volumes of parent and product solid phases. It was shown by Putnis [9] that the development of porosity is often controlled by the relative solubility of the parent and product phase in the fluid. However, it is evident from the BSE images (Fig. 2a; see 

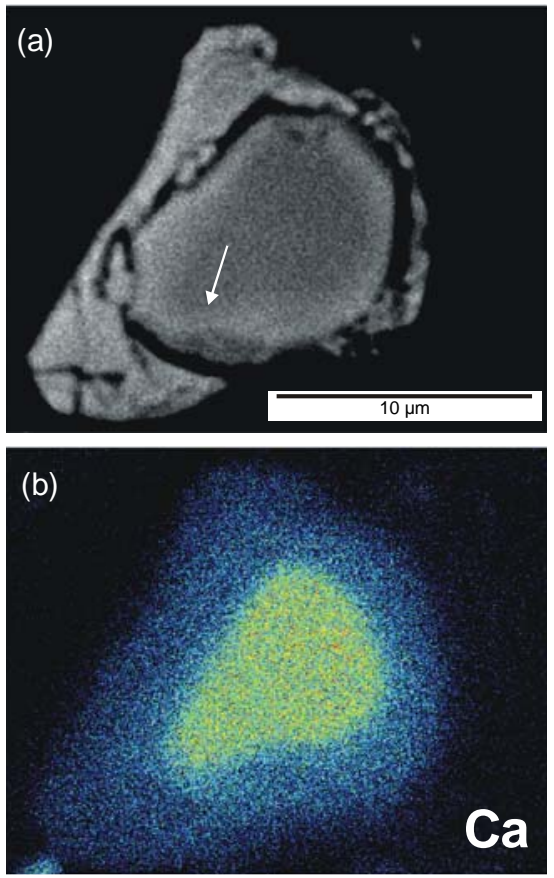

Fig. 3 (a) BSE image of a hydrothermally treated grain of the crystalline microlite. The arrow points to the interface between a reaction rim and the parent microlite. (b) A Ca distribution map of the same grain shown in (a). The reaction rim is characterized by a low Ca content compared to the parent microlite (core) and represents a highly defective pyrochlore phase. See text for more details.

also [6]) that the new defect pyrochlore does not exhibit porosity on the micrometer scale. Porosity could also be excluded from mass balance calculations based on the measured concentration of Ta in the fluid [6].

However, in order to investigate the microstructure of the defect pyrochlore, i.e. to look for nano-sized pores by TEM, an electron-transparent foil across the interface between the parent and the product pyrochlore phase was prepared by the FIB technique. Selected area electron diffraction (SAED) patterns reveal that the replacement is topotactic (Figs. 4a,b). The new defect pyrochlore is further characterized by a high density of dislocations (Fig. 4d). The most important observations, however, are (i) that defect pyrochlore does not exhibit porosity and (ii) that the $\mathrm{Ca}$ and $\mathrm{Na}$ concentration gradient at the interface is sharp on the nanometer scale (Fig. 4c).

Whereas the topotactic relationship between the parent and product pyrochlore has frequently been considered as a characteristic of a diffusion-controlled ion exchange process, it is also typical for a coupled D-R process, where dissolution occurs simultaneously with precipitation at a moving interface [9]. The latter process would be more compatible with the sharp chemical gradient seen in Fig. $4 c$ than a diffusion-based process. Furthermore, a high
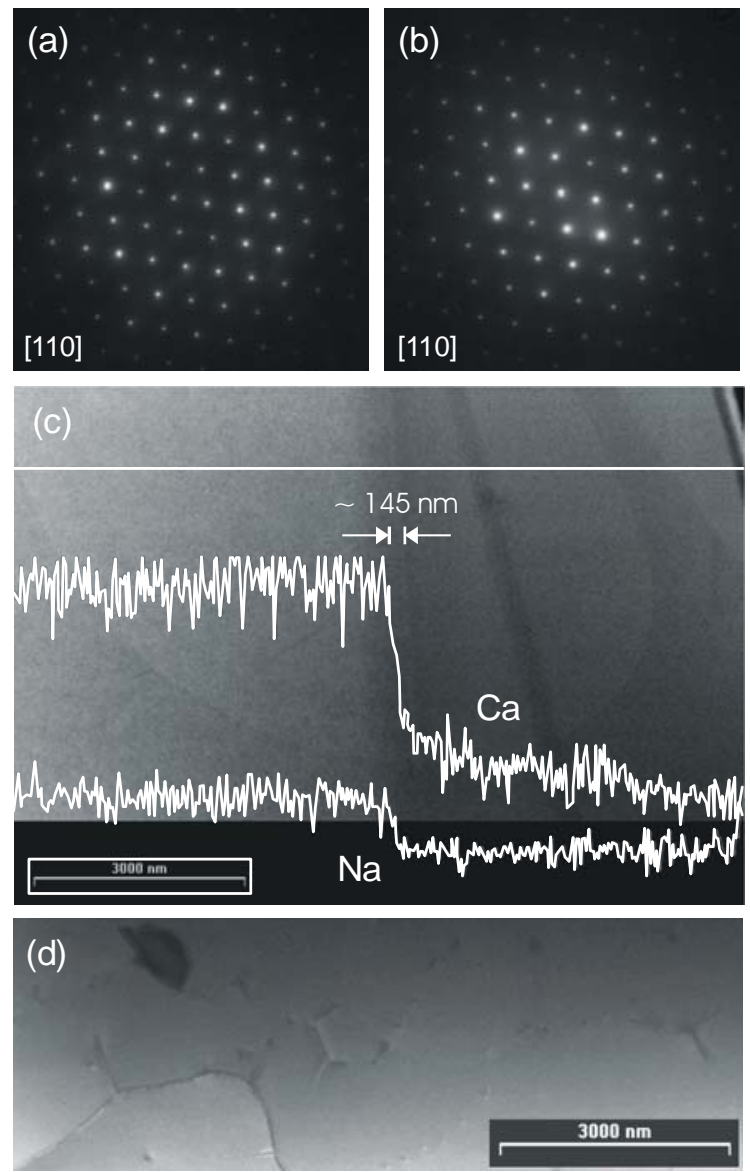

Fig. 4. TEM results from an electron transparent foil prepared by the FIB technique. The foil crosses the interface between the parent microlite and the reaction rim. (a) Selected area electron diffraction (SAED) pattern of the parent microlite (left hand side in (c)). (b) SAED pattern from the defect pyrochlore rim (right hand side in (c)). (c) Bright field (BF) image of the TEM foil along with energy-dispersive X-ray intensity profiles of $\mathrm{Ca}-\mathrm{K} \alpha$ and $\mathrm{Na}-\mathrm{K} \alpha$ radiation measured along the white line. Note the sharp chemical gradient at the interface. The contrast in the image is partly due to the underlying copper grid. (d) BF image of the defect pyrochlore rim, showing a high number of dislocations.

number of extended defects such as those seen in Fig. 4d are typical for crystals that grow from highly supersaturated solutions. A high number of dislocations were also observed in hydroxyapatite that has replaced a chlorapatite by a coupled D-R process [10]. As discussed by Geisler et al. [6], one may consider $\left(\mathrm{H}_{2} \mathrm{O}\right)_{\mathrm{x}} \mathrm{H}_{2} \mathrm{Ta}_{2} \mathrm{O}_{6}$, described in [11], as the thermodynamically stable end member in the simplified solid solution/aqueous solution system $\left(\mathrm{H}_{2} \mathrm{O}\right)_{x} \mathrm{H}_{2} \mathrm{Ta}_{2} \mathrm{O}_{6}-\left(\mathrm{Ca}, \mathrm{Na}_{2} \mathrm{Ta}_{2} \mathrm{O}_{6} \mathrm{~F}-\mathrm{HCl}-\mathrm{H}_{2} \mathrm{O}\right.$. However, as discussed by Geisler et al. [6], the circumferential cracking seen in Fig. 3a, which occurs some distance behind the interface, indicates the occurrence of stress as a result of a $3.4 \%$ larger volume of 
the defect pyrochlore. It is difficult to explain the formation of stress that caused cracking by a coupled D-R process. Nevertheless, whatever the mechanism at the interface (i.e., stoichiometric dissolution versus selective bond breaking), the fact that porosity has not been detected by TEM verifies previous conclusion that the reaction rate is controlled by solid state diffusion through the defect pyrochlore phase. The elucidation of the process, however, warrants further research.

In contrast to the microlite, the amorphous betafite-(Y) completely recrystallized to a new phase assemblage as seen in the XRD spectrum (Fig. 1b). Most of the peaks in the XRD pattern could be assigned to rutile and anatase structure but with slightly higher $d$ values compared to the pure $\mathrm{TiO}_{2}$ phases (anatase: pdf 01-071-1169; rutile: pdf 01-073-2224). In order to study the phases and their relationship by BSE imaging and EMP, we have polished one large grain to about half of its thickness. It is noteworthy that the shape of this grain is almost the same as it was before the experiment. The BSE images reveal a complex intergrowth of at least two phases and a large porosity (Fig. 2). The most frequent phase shows complex, non-equilibrium banding structures (Figs. 2b - d). Compared with the untreated betafite this phase is depleted in Y, REEs, and $\mathrm{U}$ and relative enriched in $\mathrm{Nb}$, Ti, and Ta (Fig. 2d, Fig. 5). The underlying phase can actually be identified as a mixture of anatase and rutile from electron diffraction pattern (Fig. 6b) and $\mu$-Raman measurements. From the intensity of the strongest (101) anatase and the (110) rutile reflection of the XRD spectrum and the empirical relationship given in Despero et al. [12], we can estimate that the anatase to rutile ratio is about 0.4:0.6. The banding is based on large variations of the Nb-Ti ratio (Fig. 2d, Fig. 5a). It is noteworthy that two trends can be distinguished in the diagram $\mathrm{Nb}_{2} \mathrm{O}_{5}$ versus $\mathrm{UO}_{2}$ (Fig. 5b). Whereas anatase was detected as the major phase in the Nb-rich areas by $\mu$-Raman spectroscopy, rutile dominates in areas with no more than about $30 \mathrm{wt} . \%$ $\mathrm{Nb}_{2} \mathrm{O}_{5}$ (see also Fig. 5b). We note that the $\mathrm{Nb}$ content is anomalous high for the anatase or rutile structure. Another phase appears bright in the BSE images of Figs. 2b,c. This phase is a yet unidentified Nb-Ta oxide. Two XRD reflections can be identified that do not belong to rutile or anatase, which thus may be assigned to this phase $(\mathrm{d} \approx$ $0.33 \mathrm{~nm}$ and $\mathrm{d} \approx 0.27 \mathrm{~nm}$ ). It contains almost no U, REEs, and Y. Furthermore, a minor third, yet unidentified phase could be detected, which has captured Y and REEs.

All new phases contain less $U$ than the untreated betafite-(Y) (Fig. 5b). This indicates that significant $\mathrm{U}$ was lost to the fluid phase. Indeed, we found $(11.88 \pm 0.40) \times$ $10^{-3} \mathrm{~g} \mathrm{U}$ in the fluid phase by ICP-AES. We also detected minor amounts $\mathrm{Ti}\left(=(0.075 \pm 0.0010) \times 10^{-3} \mathrm{~g}\right)$ in the fluid. From the average $U$ content in the betafite- $(\mathrm{Y})(=$ $9.8 \pm 2.2$ wt. \%) and the amount of betafite used for the experiment $(=0.17520 \mathrm{~g})$ we have estimated that $\sim 30$
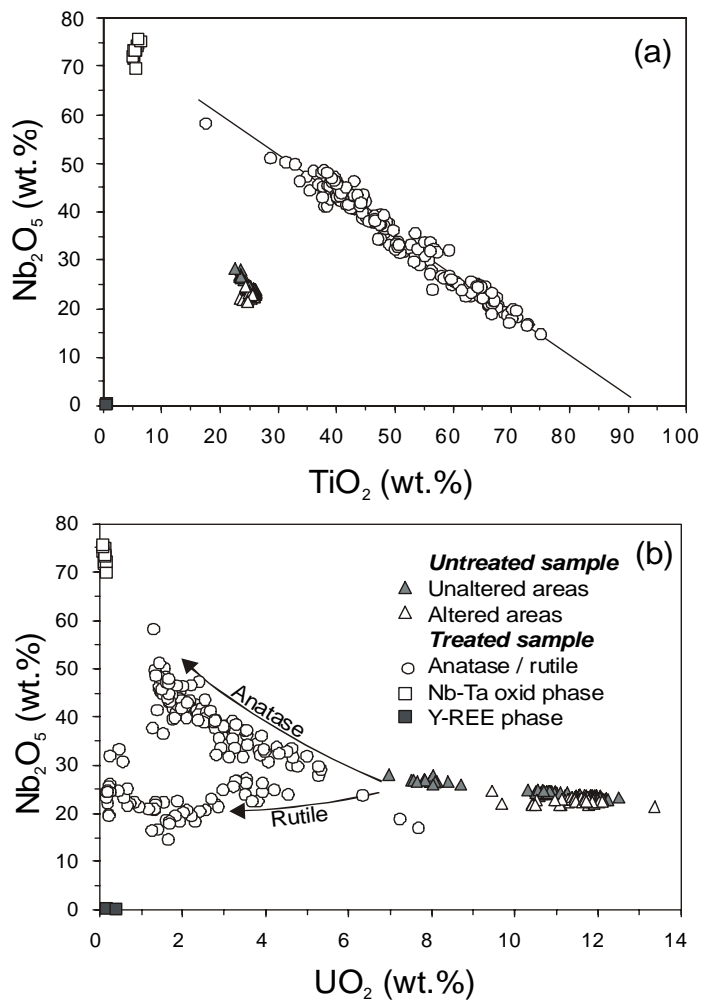

Fig. 5. Chemical variation of the alteration phases of the hydrothermally treated betafite-(Y) in a plot of (a) $\mathrm{Nb}_{2} \mathrm{O}_{5}$ versus $\mathrm{TiO}_{2}$ and (b) $\mathrm{Nb}_{2} \mathrm{O}_{5}$ versus $\mathrm{UO}_{2}$. The legend for both diagrams is shown in (b). Note that the anatase and rutile phases are unusually enriched in Nb. See text for further details-

wt.\% of the $\mathrm{U}$ of the betafite was retained in the new solid phase assemblage, i.e. that $\sim 70 \%$ was lost to the fluid phase. This estimate is in good agreement with mass balance calculations based on the phase proportions estimated from BSE images.

In order to further study the reaction mechanism, we investigate the microstructure of the banded anatase rutile phase assemblage by TEM. For this, we cut out another foil perpendicular to the banding by the FIB technique (Fig. 2c). Bright field images and SAED patterns reveal that the anatase/rutile phase assemblage is polycrystalline with a random grain orientation (Fig. 6). Based on textural considerations, it seems very likely that anatase and rutile were formed within the unaltered areas of the betafite-(Y), whereas the Nb-Ta phase (bright in the BSE images of Figs. 2d,e) crystallized within the previously altered area, i.e. along pre-existing cracks. This interpretation is consistent with the orientation of the banding, which runs away from the zones where the $\mathrm{Nb}$ Ta phase is located. Such a complex intergrowth and the polycrystalline structure of the anatase - rutile assemblage suggest that anatase and rutile were formed by a diffusion- 

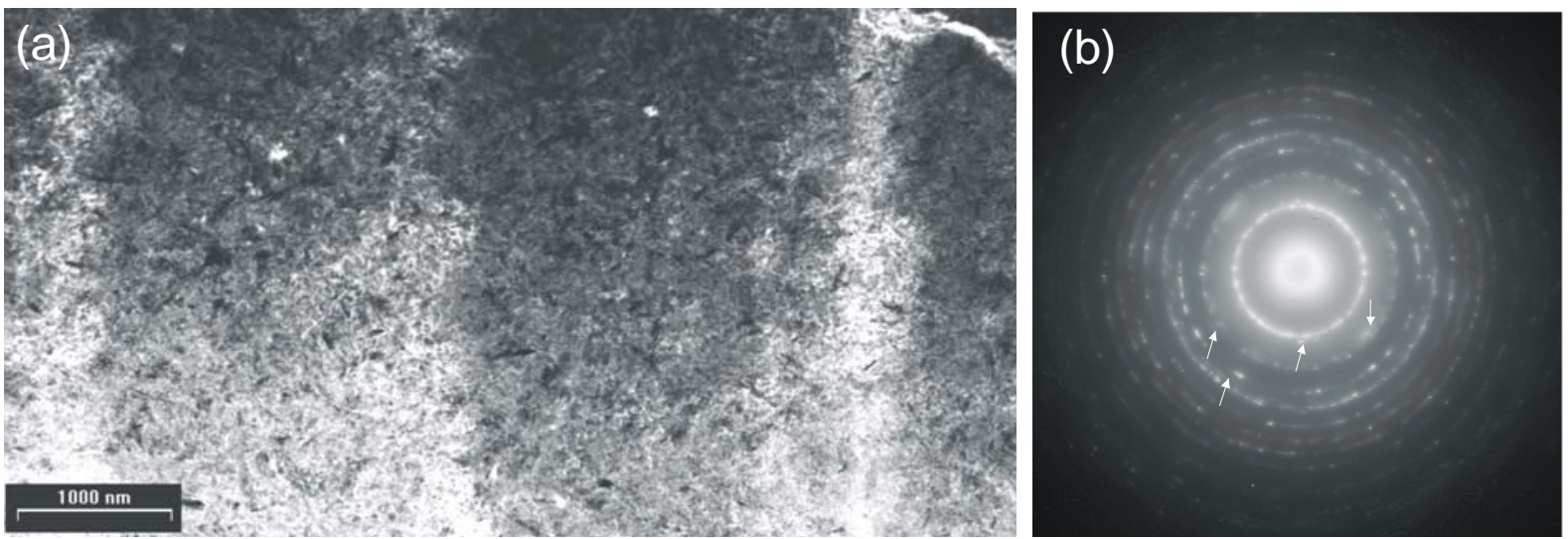

Fig. 6. TEM results on an electron transparent foil, prepared by the FIB technique from the banded area marked in Fig. 2c. (a) BF image of the foil, showing a banded and a polycrystalline structure. (c) SAED pattern from the area shown in (a). The diffraction rings are from polycrystalline anatase, whereas the additional diffraction signals marked by arrows are from rutile.

reaction process while the betafite phase was in the solid state. During the alteration process the REEs, Y, and most of the $U$ were selectively removed from the amorphous betafite, leaving behind the B-site cations, allowing the nucleation and growth of anatase and the anatase-to-rutile transformation to occur. We suggest that the diffusion of hydrogen plays a key role during such a process. It is also conceivable that the feedback, necessary for the development of patterns from an unpatterned state, is based on the well-known inhibition of grain growth of $\mathrm{TiO}_{2}$ when $\mathrm{Nb}$ is incorporated [13,14]. However, the atomistic mechanism that has generated the banding structures is not yet understood.

The occurrence of the Nb-Ta and Y-REE phases also indicates that dissolution-reprecipitation reactions are involved, suggesting a complex interplay of various processes. We note here that rutile and anatase were also found as alteration products in natural betafite $[3,4]$ and that complex, non-equilibrium structures similar to those produced experimentally have also been observed in a natural betafite crystal from Betafo, Madagascar [15]. This indicates that our experimental results are relevant for understanding natural alteration of pyrochlore and for predicting the long-term behaviour of a synthetic actinidebearing pyrochlore in the geological environment of a nuclear waste repository. However, in natural systems rutile and anatase are accompanied by liandratite (ideally $\mathrm{UNb}_{2} \mathrm{O}_{8}$ ) and uranopyrochlore as alteration products of betafite, which apparently captured most of the $U$ released from the altered betafite [3,4]. Under the experimental conditions neither liandratite nor uranopyrochlore was stable. Instead, the unidentified $\mathrm{Nb}-\mathrm{Ta}$ and $\mathrm{Y}$-REE oxides are stable phases, which did not incorporate $U$ in significant amounts, resulting in the high loss of $U$ to the fluid phase.

\section{Concluding remarks}

Our results on the aqueous alteration of crystalline and metamict pyrochlore in an acidic solution at $175^{\circ} \mathrm{C}$ indicate that the alteration proceeds via different reaction mechanisms, which are based on a complex interplay of diffusion, reaction, dissolution and reprecipitation of more stable phases. It is clear that the different chemistry of both pyrochlore samples can have an effect on their aqueous stability and also on the phase relationships. However, we emphasize that the altered volume was significantly larger in the heavily self-irradiation damaged betafite than it was in the microlite sample, indicating a strong impact of self-irradiation structural damage on the alteration kinetics.

Whatever the atomistic details of the reactions, our preliminary experimental results point to the importance of gaining a more detailed understanding of the aqueous alteration mechanisms and the impact of the radiation damage before reliable predictions about the long-term stability of an actinide-bearing titanate pyrochlore waste form in a geological environment can be made. Our observations indicate that the aqueous stability of pyrochlore-group minerals and the fluid-pyrochlore reaction mechanisms are influenced by self-irradiation structural damage and that thermodynamic equilibrium models cannot be applied to adequately describe such systems.

\section{Acknowledgements}

We would also like to thank G. Lumpkin for providing us with an Excel spreadsheet to calculate the chemical formula of pyrochlore. We are indebted to J. Schlüter from the Mineralogical Museum of the University of Hamburg for putting both samples used for the experiments at our 
disposal. We also acknowledge financial support by the Deutsche Forschungsgemeinschaft (grant GE 1094/5-1).

\section{References}

[1] A.E. Ringwood, S.E. Kesson, N.G. Ware, W. Hibberson, A. Major, Nature 278 (1979) 219.

[2] R.C. Ewing, W.J. Weber, J. Lian, J. Appl. Phys. 95 (2004) 1.

[3] G.R. Lumkin, R.C. Ewing, Am. Mineral. 81 (1996) 1237.

[4] G.R. Lumpkin, J. Nucl. Mater. 289 (2001) 136.

[5] A.M. Seydoux-Guillaume, P. Goncalves, R. Wirth, A. Deutsch, Geology 31 (2003) 973.

[6] T. Geisler, J. Berndt, H.-W. Meyer, K. Pollok, A. Putnis, Min. Mag, in press.

[7] G.R. Lumpkin, R.C. Ewing, Phys. Chem. Minerals 2 (1988) 2.

[8] R.L. Romer, S.-A. Smeds, Prec. Res. 76 (1996) 15.

[9] A. Putnis, Min. Mag. 66 (2002) 689.

[10] K. Pollok, T. Geisler, A. Putnis, Goldschmidt Conf. Abstr. (2004) A184.8

[11] P.G. Dickens, M.T. Weller, Sol. State Com. 59 (1986) 569.

[12] L.E. Despero, L. Sangaletti, B. Allieri, E. Bontempi, R. Salari, M. Zocchi, C. Casale, M. Notaro, J. Mater. Res. 13 (1998) 180.

[13] A.M. Rui, G. Dezanneau, J. Arbiol, A. Cornet, J.R. Morante, Chem. Mater. 16 (2004) 862.

[14] L.E. Depero, L. Sangaletti, B. Allieri, E. Bontempi, A. Marino, M. Zocchi, J. Cryst. Growth 198/199 (1999) 516.

[15] Own unpublished BSE images 